\title{
Gastro-protective Effects of the Methanolic Extract of the Rind of Citrullus Lanatus on Indomethacin Induced Gastric Ulceration in Male Wistar Rats
}

\author{
Tolunigba A. Kolawole ${ }^{1}$, and Datonye Victor Dapper ${ }^{2 *}$ \\ ${ }^{1}$ Department of Physiology, Faculty of Basic Medical Sciences, College of Medicine, Madonna University, PMB 48, \\ Elele, Nigeria. \\ ${ }^{2}$ Department of Human Physiology, Faculty of Basic Medical Sciences, College of Health Sciences, University of \\ Port Harcourt, PMB 5323, Port Harcourt, Nigeria.
}

\begin{abstract}
Objectives: Study investigated methanolic extract of rind of Citrullus lanatus for possible benefit in ameliorating indomethacin induced gastric ulceration.

Methodology: Adult male Wistar rats were assigned 5 groups of 6 rats each. Group 1 received extract vehicle; Groups 2, 3 and 4 received 100mg/kg, 200mg/ $\mathrm{kg}$ and $500 \mathrm{mg} / \mathrm{kg}$ bw of extract; Group 5 received $200 \mathrm{mg} / \mathrm{kg}$ bw of cimetidine. Treatment was orally for 21days. Gastric ulcer was subsequently induced by oral indomethacin. Gastric juice volume, acid concentration, ulcer index, percentage ulcer inhibition was determined. Photomicrograph sections of the gastric mucosa of the various groups were obtained.
\end{abstract}

Results: Compared to cimetidine, extract protected gastric mucosa against indomethacin induced gastric ulceration with significant reduction in gastric juice volume, acid concentration and ulcer index and increase in percent ulcer inhibition in a dose dependent manner ( $\mathrm{p}<0.05)$; consistent with gastric histological changes.

Conclusion: Extract of the rind of Citrullus lanatus exerts potential gastro-protective effects against indomethacin induced gastric ulceration in male Wistar rats.

Keywords: Citrullus lanatus, gastric protection, gastric ulcer, indomethacine

\section{INTRODUCTION}

Although many useful drugs have been identified in the treatment of ulcers, these drugs are often accompanied with undesirable side effects such as drowsiness, muscular pain, diarrhea, fatigue and headache. ${ }^{1}$ Watermelon (Citrullus lanatus), is a fruit with about $93 \%$ water which gives it the name "watermelon". The Citrullus part of watermelon is derived from the Greek word 'citrus;' while lana-

*Corresponding author: Professor Datonye Victor Dapper. E-mail: victor.dapper@uniport.edu.ng (Received 19 August 2017, accepted 21 September 2017) 
tus, a Latin word meaning wooly, describes the tiny hairs present on the stems and leaves of the plant. ${ }^{2}$ Watermelon has been cultivated in Africa for over 4,000 years. ${ }^{3}$ It is a very rich natural source of lycopene; an antioxidant with potential health benefits. ${ }^{4,5}$ It also belongs to the family of Cucurbitacea plants which are known to possess bioactive compounds like alkaloids, triterpenes, sterols and cucurbitacin. ${ }^{6}$ The various parts of watermelon have beneficial values and these include the rind and seeds. The rind which is the thick smooth exterior part of the fruit has been reported to be prescribed in cases of diabetes and alcoholic poisoning. ${ }^{7}$ The rind contains alkaloids, saponin, cardiac glycosides, flavonoids, phenol, moisture, lipid, protein, fiber, and carbohydrates. ${ }^{8}$ In a recent report from our center, we described the possible ameliorative effects of the methanolic extract of the rind of Citrullus lanatus on semen parameters and reproductive hormones following lead acetate induced toxicity in male wistar rats. ${ }^{9}$

Plant based medicines are now considered as better alternatives to control and treatment of various diseases; because of safety considerations since they have minimal side effects likely due to the presence of naturally occurring ingredients. ${ }^{10}$ On account of these, the present study attempted to evaluate the methanolic extract of the rind of Citrullus lanatus for possible benefit in indomethacin induced gastric ulceration using male Wistar rats as models.

\section{METHODOLOGY}

\section{Plant material and preparation of extracts}

Fresh plant and fruits of watermelon were obtained from a local market in Rivers State, Nigeria. The fruits were identified and authenticated by Dr. C Ekeke of the Department of Plant Science and Biotechnology, University of Port Harcourt, Nigeria. Herbarium number: UPH/V/1214 was assigned and voucher specimens deposited. The rinds were peeled off from the whole fruit washed thoroughly, sun-dried and milled into a fine powder. The method of extraction employed is percolation as described by Adesanya et. al., 2011. ${ }^{11} 24 \mathrm{~g}$ of the powdered sample was soaked in a beaker containing $100 \mathrm{ml}$ of $98 \%$ methanol for a period of 48 hours and then filtered with a Whatman No. 1 filter paper size. The volume of filtrate obtained was $150 \mathrm{ml}$ before concentration; the filtrate was subsequently concentrated using a rotary evaporator. The weight of residue obtained was 8.5g. The study protocol was approved by the College Research Ethics Committee, College of Health Sciences, University of Port Harcourt, Nigeria with the reference number: UPH/CHS/CREC/2011/Ao35 vide a communication dated $24^{\text {th }}$ April 2011. Furthermore, the study was conducted in accordance with the guidelines for the care and use of laboratory animals issued by the United States Institute for Laboratory and Animal Research (1996). ${ }^{12}$ 


\section{Determination of Median Lethal Dose $\left(\mathrm{LD}_{50}\right)$}

Acute toxicity study $\left(\mathrm{LD}_{50}\right)$ was determined using the method described by Lorke $1989 .{ }^{13}$ The $\left(\mathrm{LD}_{50}\right)$ of the extract was found to be greater than $2000 \mathrm{mg} / \mathrm{kg}$ body weight.

\section{Experimental design}

Thirty male Wistar rats were used for this study. The rats were aged 8 to10 weeks and weighed between 170 and 200g. They were randomly divided into five groups: Groups 1 to 5 consisting of 6 rats each. Rats in each group were numbered 1 to 6 and placed in separate cages in the Animal House of Madonna University, Nigeria under natural day and night cycles. The rats had free access to normal rat chow and tap water ad libitum. They were allowed two weeks of acclimatization to their environment and subsequently treated as follows:

Group 1: Control group; rats in this group were given $2 \mathrm{ml} / \mathrm{kg}$ body weight of extract vehicle.

Group 2: Low dose extract group; rats in this group were treated with 10omg/ $\mathrm{kg}$ body weight of the extract of the rind of Citrullus lanatus.

Group 3: Medium dose extract group; rats in this group were treated with $200 \mathrm{mg} / \mathrm{kg}$ body weight of the extract of the rind of Citrullus lanatus.

Group 4: High dose extract group; rats in this group were treated with 500mg/ $\mathrm{kg}$ body weight of the extract of the rind of Citrullus lanatus.

Group 5: Positive control group; rats in this group were given 200mg/kg body weight of Cimetidine.

The extract of the rind of Citrullus lanatus, cimetidine and extract vehicles were administered to the rats daily, using an oral cannula. All the rats were treated for a total of 21 days.

\section{Induction of gastric ulceration}

After 21 days of treatment, the rats were fasted for 24 hours following which gastric ulceration was induced by oral administration of $40 \mathrm{mg} / \mathrm{kg}$ body weight of indomethacin.

\section{Determination of gastric juice volume, gastric acid secretion, and ulcer index}

This was performed as earlier described by Heeba et. al., 2009. ${ }^{14}$ Four hours after the induction of gastric ulcer, the rats were killed by cervical dislocation, the abdomen was opened to remove the stomach, and gastric contents was collected to determine the gastric juice volume. Five milliliters of distilled water was add- 
ed to the gastric juice and the resultant solution was centrifuged at 3,000 rpm for 10 minutes. Gastric juice acid concentration in $\mathrm{mEq} / \mathrm{L}$ was determined in the supernatant volume by titration to $\mathrm{pH} 7$ with $0.0025 \mathrm{~N}$ of sodium hydroxide.

After removal of gastric content from the stomach, the stomach was pinned onto a soft board. Scoring of ulcer was subsequently done as follows: $1=$ erosions of $1 \mathrm{~mm}$ or less in diameter; 2 = erosions of between 1 to $2 \mathrm{~mm}$ in diameter; $3=$ erosions greater than $2 \mathrm{~mm}$ in diameter. The overall scores were divided by a factor of 10 and the result obtained designated as the ulcer index..$^{15}$ The percentage of ulcer inhibition was also calculated as follows:

Percent ulcer inhibition $=\frac{(\text { Mean ulcer index of control-Mean ulcer index of test })}{\text { Mean ulcer index of control }} \times 100$

\section{Gastric histology}

Portions of the stomach of all rats were carefully obtained and fixed in 10\% formalin, dehydrated stepwise in graded alcohol, cleared in xylene and then embedded in liquid paraffin. A $5 \mu$ thickness paraffin section was cut and stained in hematoxylin and eosin, followed by examination under a light microscope at x200 magnification. The slides obtained were analyzed and then re-analyzed by two different but widely experienced pathologists. Appropriate photomicrographs were subsequently obtained. Typical results for each respective Group are as presented in Plates A to E.

\section{Statistical analysis}

The results of this study were expressed as mean and standard error of mean (Mean \pm SEM). Significant differences between the groups was assessed using the one-way analysis of variance (ANOVA); followed by the LSD post-hoc test. A p value less than 0.05 was considered statistically significant. Results are as presented in Table 1 and Plates A to E. 
Table 1. Effects of the methanolic extract of the rind of Citrullus lanatus on gastric juice volume, gastric juice acid concentration, gastric ulcer index, and percentage ulcer inhibition in male Wistar rats.

\begin{tabular}{|c|c|c|c|c|c|}
\hline Groups & $\begin{array}{c}\text { Group 1: } \\
\text { Control } \\
\text { group } \\
\text { [2ml/kg bw } \\
\text { of extract } \\
\text { vehicle] }\end{array}$ & $\begin{array}{c}\text { Group 2: } \\
\text { Low dose } \\
\text { extract } \\
\text { group } \\
\text { [100mg/ } \\
\text { kg bw of } \\
\text { extract] }\end{array}$ & $\begin{array}{c}\text { Group 3: } \\
\text { Medium } \\
\text { dose extract } \\
\text { group } \\
\text { [200mg/ } \\
\mathrm{kg} \mathrm{bw} \mathrm{of} \\
\text { extract] }\end{array}$ & $\begin{array}{c}\text { Group 4: } \\
\text { High dose } \\
\text { extract } \\
\text { group } \\
\text { [500mg/ } \\
\mathrm{kg} \mathrm{bw} \mathrm{of} \\
\text { extract] }\end{array}$ & $\begin{array}{c}\text { Group 5: } \\
\text { Cimetidine } \\
\text { group } \\
\text { (Positive } \\
\text { control) } \\
{[200 \mathrm{mg} /} \\
\mathrm{kg} \mathrm{bw} \mathrm{of} \\
\text { Cimetidine] }\end{array}$ \\
\hline $\begin{array}{c}\text { Gastric juice } \\
\text { volume } \\
\text { [ml/4hr] }\end{array}$ & $5.26 \pm 0.08$ & $5.22 \pm 0.08$ & $5.16 \pm 0.05^{*}$ & $5.14 \pm 0.05^{*}$ & $5.02 \pm 0.04^{*}$ \\
\hline $\begin{array}{c}\text { Gastric } \\
\text { juice acid } \\
\text { concentration } \\
\text { [mEq/L] }\end{array}$ & $0.81 \pm 0.13$ & $0.57 \pm 0.03^{*}$ & $0.66 \pm 0.03^{*}$ & $0.50 \pm 0.03^{*}$ & $0.53 \pm 0.08^{*}$ \\
\hline $\begin{array}{c}\text { Gastric ulcer } \\
\text { index }\end{array}$ & $2.76 \pm 0.06$ & $2.36 \pm 0.15^{*}$ & $1.21 \pm 0.08^{*}$ & $0.50 \pm 0.08^{*}$ & $1.20 \pm 0.14^{*}$ \\
\hline $\begin{array}{c}\text { Percentage } \\
\text { ulcer } \\
\text { inhibition } \\
\text { [\%] }\end{array}$ & - & $14.5^{*}$ & $56.2^{*}$ & $81.9^{*}$ & $56.5^{*}$ \\
\hline
\end{tabular}

Values expressed as Mean \pm SEM; * significantly different as compared to control

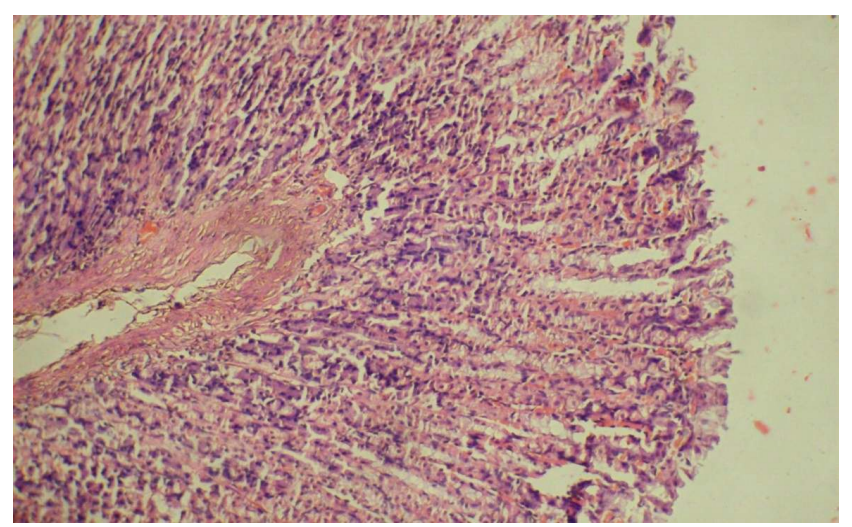

Plate A. Cross section of gastric epithelium of Group 1 control rats (Ulcerated untreated group)

Plate A is a cross section of the gastric epithelium obtained from Group 1 ulcerated and untreated control rats showing blood stained hemorrhagic ulcers, a disrupted epithelium and blood-stained mucosa. 


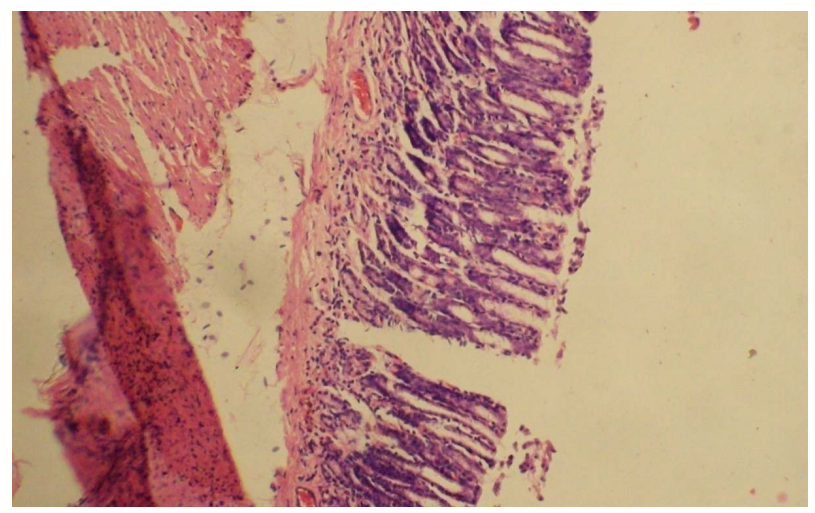

Plate B. Cross section of gastric epithelium of Group 2 rats (Low dose extract group)

Plate B is a cross section of the gastric epithelium obtained from Group 2 low dose extract treated rats showing severe disintegration of the epithelial cells.

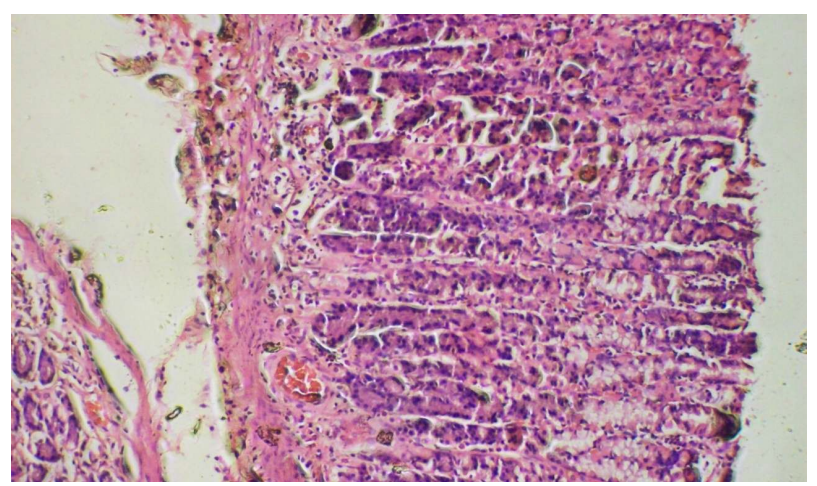

Plate C. Cross section of gastric epithelium of Group 3 rats (Medium dose extract group) Plate $\mathrm{C}$ is a cross section of the gastric epithelium obtained from Group 3 medium dose extract treated rats showing severe erosion of the mucosa layers and evidence of mild ulceration.

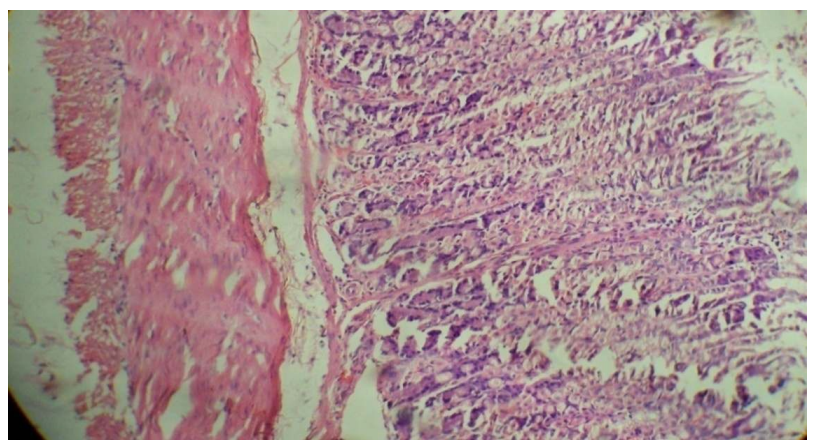

Plate D. Cross-section of gastric epithelium of Group 4 rats (High dose extract group) 
Plate D is a cross-section of gastric epithelium obtained from Group 4 high dose extract treated rats showing a fairly intact and tightly arranged epithelial cells with slight disruption of the uppermost epithelium of the mucosa.

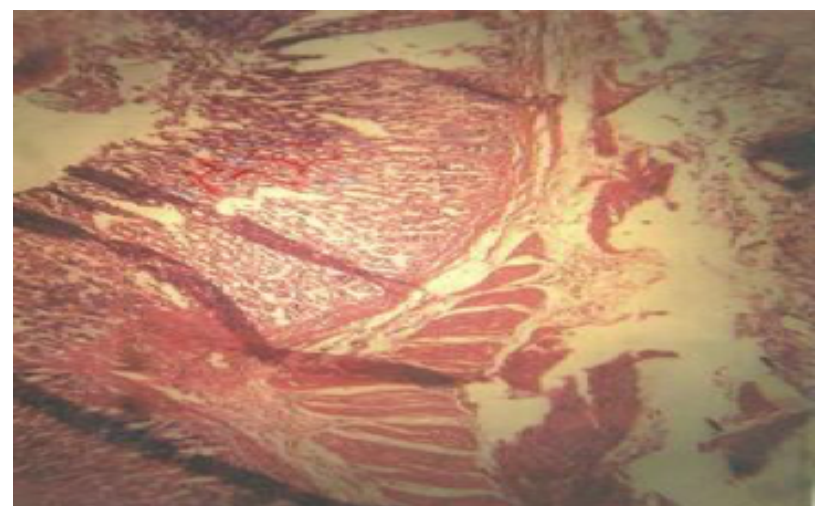

Plate E. Cross-section of gastric epithelium of Group 5 rats (Cimetidine/positive control group)

Plate $\mathrm{E}$ is a cross-section of the gastric epithelium obtained from Group 5 cimetidine treated positive control rats showing minimal disruption of the gastric epithelium and blood stained mucosa.

\section{RESULTS AND DISCUSSION}

Effects of the extract of Citrullus lanatus on gastric juice volume, gastric acidity, ulcer index and percentage ulcer inhibition

Table 1 shows the effects of the extract the rind of Citrullus lanatus on gastric juice volume, gastric juice acid concentration, mean ulcer index and percentage ulcer inhibition in male Wistar rats in the present study. At doses of 200 and $500 \mathrm{mg} / \mathrm{kg}$ body weight the extract significantly reduced gastric juice volume in a dose dependent manner ( $\mathrm{p}<0.05)$, compared to rats in the control group (Group 1). This effect is similar to that of the administration of cimetidine at a dose of 200mg/kg body weight seen amongst rats in Group 5. Similarly, at all doses administered, the extract significantly reduced gastric juice acid concentration amongst Groups 2, 3 and 4 rats ( $\mathrm{p}<0.05)$, an effect comparable to that of cimetidine at a dose of $200 \mathrm{mg} / \mathrm{kg}$ body weight. Furthermore, at all doses administered, the extract significantly reduced the mean ulcer index in a dose dependent manner ( $\mathrm{p}<0.05$ ) compared to rats in the control group (Group 1). This effect of the extract was observed to be also similar to those induced by the administration of cimetidine at a dose of 200mg $/ \mathrm{kg}$ body weight amongst Group 5 rats. At all doses, administration of the extract caused a significant increase in percentage ulcer inhibition in a dose dependent manner $(\mathrm{p}<0.05)$, similar to the effect of cimetidine and comparable to rats in the control group (Group 1). 


\section{Histologic changes in the gastric epithelium}

Plate A is a cross section of the gastric epithelium obtained from Group 1 ulcerated and untreated (control) rats showing blood stained hemorrhagic ulcers, a disrupted epithelium and blood stained mucosa. Plate B is a cross section of the gastric epithelium obtained from Group 2 low dose extract treated rats showing severe disintegration of the epithelial cells. Plate $\mathrm{C}$ is a cross section of the gastric epithelium obtained from Group 3 medium dose extract treated rats showing severe erosion of the mucosa layers and evidence of mild ulceration. Plate $\mathrm{D}$ is a cross-section of gastric epithelium obtained from Group 4 high dose extract treated rats showing a fairly intact and tightly arranged epithelial cells with slight disruption of the uppermost epithelium of the mucosa. Plate $\mathrm{E}$ is a cross-section of the gastric epithelium obtained from Group 5 cimetidine treated positive control rats showing minimal disruption of the gastric epithelium and blood stained mucosa.

The present study attempted to determine the possible beneficial effects of the extract of the rind of Citrullus lanatus against indomethacin induced ulceration of the gastric mucosa in male Wistar rats. The results obtained indicating a reduction in gastric juice volume, gastric juice acid concentration and mean ulcer index and an increase in percent ulcer inhibition, clearly suggest that the extract of Citrullus lanatus apparently protected the gastric mucosa against indomethacin induced ulceration in a dose dependent manner; comparable to the effect of cimetidine a known histamine $\left(\mathrm{H}_{2}\right)$ receptor antagonist used commonly in the management of peptic ulcer disease. The possible active ingredients in the rind of Citrullus lanatus responsible for its protective effects are at present uncertain. However, phytochemical screening has revealed the presence of tannins and flavonoids amongst other constituents. ${ }^{8}$ These compounds have been shown to have a contributory role in ameliorating the development of peptic ulcers: tannins are known to 'tar' the outermost layer of the gastric mucosa rendering it less permeable and more resistant to chemical and mechanical injury or irritation. ${ }^{16}$ It is possible that flavonoids present in the rind of Citrullus lanatus may also play a role in this regard: flavonoids possess antioxidant properties in addition to strengthening the mucosal defense system through stimulation of gastric mucus secretion..$^{17}$

The findings of this study also suggest that watermelon rind causes a significant reduction in gastric acid secretion. When compared with the control group, all treatment groups exhibited a decrease in gastric acid output. The results also suggest that watermelon rind inhibits gastric acid secretion in a dose dependent manner. It has been earlier reported that nitric oxide inhibits gastric acid secretion in rats. ${ }^{18}$ Watermelon rind is an edible source of citrulline; a compound vital 
for the production of nitric oxide. Watermelon consumption increases the level of citrulline significantly. ${ }^{19}$ It is therefore safe to propose that one of the possible mechanisms by which watermelon rind causes a decrease in gastric acid secretion is by increasing citrulline levels thereby stimulating an increase in nitric oxide production. This will lead to a decrease in gastric acid secretion as confirmed by previous reports ${ }^{20,21}$ which in turn accounts, at least in part, for the observed gastro-protective effects of watermelon rind in indomethacin-induced gastric ulceration described in the present study. It is also pertinent to state that other mechanisms of gastric mucosal protection such as increase in mucus secretion, stimulation of prostaglandins release, increase in mucosal blood flow etc., could also be potentially involved in the anti-ulcerative actions of watermelon rind. However, these effects were not investigated in the present study. The histological changes described in the present study are fairly consistent with findings on gastric juice volume, gastric juice acid concentration, gastric ulcer index, and percentage ulcer inhibition as presented in Table 1.

In conclusion, the results of the present study show that the methanolic extract of the rind of Citrullus lanatus reduces gastric juice volume, gastric juice acid concentration, mean ulcer index and increases percentage ulcer inhibition following indomethacin induced gastric ulceration in male Wistar rats; these findings along with the histological changes described suggests a possible beneficial and potential gastric protective and anti-ulcer effects of the extract. The results indicate a possible beneficial effect of the rind of Citrullus lanatus and perhaps a therapeutic potential in the management of peptic ulcer disease. We therefore recommend further studies in this regard.

\section{REFERENCES}

1. Waldum HL, Gustafsson B, Fossmark R, Qvigstad G. Antiulcer drugs and gastric cancer. Dig Dis Sci. 2005; 50, 39-44.

2. Erhirhie EO, Ekene NE. Medicinal values on Citrullus lanatus (Watermelon): Pharmacological Review. Int J Res Pharmaceut Biomed Sc. 2013, 4(4): 1305-1312

3. Robinson RW, Decker-Walters DS. Cucurbits. CAB International. (Crop Production Science in Horticulture nE.6). New York 1997, 226.

4. Rhodes B, Zhang XP. Hybrid seed production in watermelon. J New Seed. 1999, 1, $69-88$.

5. Mandel H, Levy N, Izkovitch S, Korman SH. Elevated plasma citrulline and arginine due to consumption of Citrullus vulgaris (watermelon). J Inherit Metab Dis. 2005, 28(4), 467-472.

6. Yuan G, Wahlqvist ML, He G, Yang M, Li D. Natural products and anti-inflammatory activity. Asia Pac J Clin Nutr. 2006, 15(2), 143-152.

7. Duke JA, Ayensu ES. Medicinal plants of China. 1985. Reference Publications.

8. Erukainure OL, Oke OV, Daramola AO, Adenekan SO, Umanhonlen EE. Improvement of the biochemical properties of watermelon rinds subjected to Saccharomyces cerevisae solid media 
fermentation. Pak J Nutr. 2010, 9(8), 806-809.

9. Kolawole TA, Dapper DV and Ojeka SO. Ameliorative effects of the methanolic extract of the rind of Citrullus lanatus on lead acetate induced toxicity semen parameters and reproductive hormones of male albino wistar rats. Eur J Medi Plants. 2014, 4(9), 1125-1137.

10. Reyes-Chilpa R, Baggio CH, Alavez-Solano D, Estrada-Muñiz E, Kauffman FC, Sanchez RI, Mesia-Vela S. Inhibition of gastric $\mathrm{H}+, \mathrm{K}+-\mathrm{ATPase}$ activity by flavonoids, coumarins and xanthones isolated from Mexican medicinal plants. $J$ Ethnopharmacol. 2006, 105(1-2), 167-172.

11. Adesanya AO, Olaseinde OO, Oguntayo OD, Otulana JO, Adefule AK. Effects of methanolic extract of Citrullus lanatus seed on experimentally induced prostatic hyperplasia. Eur J Medi Plants. 2011, 1(4), 171-179.

12. Institute for Laboratory and Animal Research. Guide for the care and use of laboratory animals. Seventh Edition. National Academies Press. 1996. Washington DC, USA.

13. Lorke D. A new approach to practical acute toxicity testing. Arch Toxicol. 1983; 54(4):275287.

14. Heeba GH, Hassan MK, Amin RS. Gastroprotective effect of simvastatin against indomethacin-induced gastric ulcer in rats: role of nitric oxide and prostaglandins. Eur J Pharmacol. 2009, $607(1-3), 188-193$.

15. Main IH, Whittle BJ. Investigation of the vasodilator and anti-secretory role of prostaglandins in the rat gastric mucosa by use of non-steroidal anti-inflammatory drugs. Br J Pharmacol. 1975, 53(2), 217-224.

16. Asuzu IU, Onu OU. Anti-ulcer activity of the ethanolic extract of Combretum dolichopetalum root. Int J Crude Drug Res. 1990, 28, 27-32.

17. Martin MJ, Marhuenda E, Perrez-Guerrero C, Franco JM. Antiulcer effect of narinjin on gastric lesion induced by ethanol in rats. Pharmacology. 1994, 49(3), 144-150.

18. Hasebe K, Horie S, Komasako M, Yano S, Watanabe K. Stimulatory effects of nitric oxide donors on gastric acid secretion in isolated mouse stomach. Eur J Pharmacol. 2001, 420(2-3), 159-164.

19. Rimando AM, Perkins-Veazie PM. Determination of citrulline in watermelon rind. $J$ Chromatogr A. 2005, 1078(1-2), 196-200.

20. Brown JF, Hanson PJ, Whittle BJ. The nitric oxide donor, S-nitroso-N-acetyl-penicillamine, inhibits secretory activity in rat isolated parietal cells. Biochem Biophys Res Commun. 1993, 195(3), 1354-1359.

21. Kato S, Kitamura M, Korolkiewicz RP, Takeuchi K. Role of nitric oxide in regulation of gastric acid secretion in rats: effects of NO donors and NO synthase inhibitor. Br J Pharmacol. 1998, 123(5), 839-846. 